\title{
REAVI
}

\section{UMA ABORDAGEM SOBRE CRIATIVIDADE E GESTÃO DE IDEIAS EM EMPRESAS DE SÃO BENTO DO SUL}

\author{
Andréa Maristela Bauer Tamanine ${ }^{1}$, José Carlos Chaves Vieira ${ }^{2}$, Simone Lesnhak Willemannn ${ }^{3}$ \\ ${ }^{1}$ atamanine@yahoo.com.br, ${ }^{2}$ zephisicks@gmail.com, ${ }^{3}$ si.lk@hotmail.com
}

\section{Resumo}

Este artigo traz uma parte dos resultados de uma pesquisa aplicada pelo Projeto Ideando, da Univille, a empresas participantes do ENIT - Feira e Encontro de Negócios, Inovação e Tecnologia, realizado em 2018, no munícipio de São Bento do Sul - SC. A abordagem quantitativa ofereceu dados sob a ótica de ambientes criativos, uso de ferramentas de gestão de ideias e a percepção sobre a relação entre gestão de ideias e inovação. Como resultado, destaca-se que a cultura organizacional e suas práticas de geração e gestão de ideias parecem carecer de estruturação e que a cultura da inovação ainda é fator estratégico a ser melhor compreendido pelas empresas da região, necessitando, portanto de pesquisas mais aprofundados e abrangentes.

Palavras-chave: Criatividade. Gestão de Ideias. Inovação.

\section{AN APPROACH TO CREATIVITY AND IDEA MANAGEMENT IN SÃO BENTO DO SUL COMPANIES}

\begin{abstract}
This article presents part of the results of a research applied by Univille's Ideando Project to companies participating in ENIT - Business, Innovation and Technology Fair and Meeting, held in 2018, in the municipality of São Bento do Sul - SC. The quantitative approach provided data from the perspective of creative environments, use of idea management tools, and insight into the relationship between idea management and innovation. As a result, it is emphasized that the organizational culture and its ideas generation and management practices seem to lack structure and that the culture of innovation is still a strategic factor to be better understood by companies in the region, thus requiring more in-depth and comprehensive research.
\end{abstract}

Keywords: Creativity. Idea Management. Innovation.

\section{Introdução}

Com base nos pressupostos teóricos da Inovação Aberta, o Projeto Ideando foi proposto em 2018 à Univille, campus São Bento do Sul, como um meio de buscar compartilhamento e aplicação do conhecimento científico e tecnológico para atender às demandas da sociedade. Neste sentido, programas de geração de ideias são ferramentas fundamentais para a dinamização dos processos de criação e transferência de conhecimento e tecnologia em abordagens de inovação aberta, apoiando-se em pressupostos como confiança, compartilhamento e cocriação.

Neste sentido, no ano de 2018, o Projeto Ideando participou da sexta edição do ENIT Feira e Encontro de Negócios, Inovação e Tecnologia, evento realizado no munícipio de São Bento do Sul - SC. O objetivo do ENIT é "O desenvolvimento socioeconômico através do fomento à geração de negócios, cultura da inovação, empreendedorismo, ciência e tecnologia das empresas

Revista Eletrônica do Alto Vale do Itajaí - REAVI, v.08, n 13, p. 095-102, dez 2019 ISSN: 23164190, DOI 10.5965/2316419008112019095 
e instituições participantes". Entendendo a feira multisetorial como uma oportunidade de buscar conhecimento, foi aplicada pesquisa entre empresas expositoras visando identificar se a criatividade era estimulada e se as ideias eram geradas e geridas nas empresas.

Neste artigo se faz um recorte de resultados desta pesquisa, dando foco a três fatores indagados: ambientes criativos, o uso de ferramentas de gestão de ideias e a percepção sobre a relação entre gestão de ideias e inovação.

\section{Fundamentação Teórica}

\subsection{A criatividade e a inovação}

A contemporaneidade exige mais criatividade. É preciso ser diferente, fazer diferente. Para isso, ser criativo é fundamental. A partir da necessidade de ser criativo e atender às expectativas atuais, torna-se relevante compreender os conceitos de criatividade e saber como ela pode ser desenvolvida.

Bahia e Ibérico-Nogueira [2005] apresentam três correntes sobre teorias relacionadas à criatividade: a] o ato criativo é resultado de um processo inconsciente; b] o ato criativo é resultado de uma inspiração súbita; c] a criatividade é inerente a um gênio, que concentra as qualidades e características criativas. Segundo as autoras, esses "mitos" passaram a dominar as afirmações sobre o processo criativo durante certo tempo, em que se buscava explicar mentes geniais como as de Mozart, por exemplo.

Muitos teóricos se referem à criatividade como algo impossível de definir e de descrever, pois os atos criativos não obedecem a critérios de frequência e de previsibilidade. Entretanto, as tentativas de definição e do ensino-aprendizagem da criatividade continuam em um mundo onde inovar é imperativo. [Bahia e Ibérico-Nogueira, 2005]

Dini et al [2014] estudaram o conceito de criatividade relacionado a diversas áreas do conhecimento: Artes, Psicologia, Sociologia, etc. Perceberam que as diferentes áreas do conhecimento contribuem para a construção dos conceitos de criatividade, apontando para definições que envolvem os mesmos mitos/crenças de que "a criatividade era uma habilidade de poucos indivíduos" e que as definições passaram a entender que ela é um "potencial humano a ser desenvolvido e que quando cultivado em grupo pode gerar uma força exponencial para a criatividade" [Dini et al, 2014, p. 8].

Fatores como perfil individual dos funcionários, liderança, ambientes criados dentro de uma organização, influências socioeconômicas e políticas podem determinar a criatividade. Nesse sentido, criatividade pode ser inerente, mas é afetada por fatores externos. Assim, a partir destes conceitos e com apoio em teorias de vertentes histórico-culturais sobre a aprendizagem e desenvolvimento, se pode compreender que a criatividade dos indivíduos é resultado de duas dimensões: a interna e a externa.

Dini et al [2014], baseando-se nas pesquisas de Alencar [1995], listaram elementos estimuladores à criatividade: ambiente físico; comunicação; desafios; características da chefia; estrutura organizacional; liberdade e autonomia; participação; recursos tecnológicos e materiais; salários e benefícios; suporte da chefia e do grupo de trabalho; treinamento. Ainda, citam que esses e alguns outros fatores constituem-se como estímulos à criatividade no ambiente de trabalho: suporte da organização - o reconhecimento do trabalho criativo e cultura voltada para a inovação; estrutura organizacional menos hierárquica, normas mais flexíveis e menos burocracia; apoio da

Revista Eletrônica do Alto Vale do Itajaí - REAVI, v.08, n 13, p. 095-102, dez 2019 ISSN: 23164190, DOI 10.5965/2316419008112019095 
chefia com mais receptividade; flexibilidade e aceitação de novas ideias; suporte do grupo de trabalho com mais diálogo e confiança entre os membros.

Já em relação à inovação, esta é definida no ordenamento jurídico brasileiro, no art. $2^{\circ}$, inciso IV da Lei n. 10.973, de 2 de dezembro de 2004 (Lei de Inovação) como "introdução de novidade ou aperfeiçoamento no ambiente produtivo e social que resulte em novos produtos, serviços ou processos ou que compreenda a agregação de novas funcionalidades ou características a produto, serviço ou processo já existente que possa resultar em melhorias e em efetivo ganho de qualidade ou desempenho".

Para os autores [Chibás et al, 2014, citando Chibás, 2000], as pessoas tendem a unificar os significados de inovação e criatividade e explicam que esses dois termos possuem diferenças: enquanto a criatividade se refere mais a processos internos da criação propriamente dita, à elaboração de ideias e projetos, o termo inovação se refere mais a resultados, produtos ou efeitos da criatividade.

Em consequência, mesmo que às vezes se confundem, a gestão da inovação e da criatividade não são o mesmo processo. A gestão da criatividade refere-se mais aos aspectos subjetivos envolvidos na inovação, tais como o processo de criação da ideia pelos talentos da organização, gerenciamento do clima da equipe ou organização, inteligência emocional, estilos de liderança criativa, valores assumidos pelos participantes do processo, entre outros elementos. Enquanto a gestão da inovação referese mais aos aspectos "hard" ou de resultados esperados que se esperam da equipe e da organização [Chibás 2012 apud Chibás et al, 2014, p. 18].

Ambos processos, gestão da criatividade e gestão da inovação, devem andar em paralelo e ter total integração, mas isso nem sempre acontece, sendo que, dependendo da orientação e conhecimento de base dos gestores, tende-se a priorizar um processo ou outro. Neste ambiente de pressão cotidiana e competição, a tendência predominante é a de priorizar a gestão da inovação [Chibás et al, 2014].

Fornecidos alguns dos conceitos norteadores sobre a relação entre criatividade e inovação aqui adotados, a seção seguinte abordará os sistemas de gestão de ideias "como um subprocesso da gestão da inovação focado na geração, avaliação e seleção de ideias que podem levar à implementação de melhorias e inovações" [Quandt et al, 2014, p. 180].

\subsection{Gestão da inovação e geração de ideias}

Chibás et al [2014] realizaram uma pesquisa para analisar criticamente os fatores essenciais da gestão da inovação dentro das empresas. No seu trabalho, foram apresentadas ideias de alguns dos autores clássicos e tendências da gestão da criatividade e gestão da inovação. Segundo as leituras, os autores definiram que "A gestão da inovação tem início na criatividade - ou no caos e segue depois um processo estruturado, de definição de estratégias, de estabelecimento de prioridades, de avaliação de ideias, de gestão de projetos e de monitoramento de resultado" [Chibás et al, 2014, p. 20].

Quanto aos fatores internos, citando [Van Dijk e Van den Ende, 2002], [Quandt et al, 2014] destacam a importância de construir uma cultura e estrutura organizacionais para a inovação, com clareza da missão, estratégias e atitudes a favor da inovação no ambiente de trabalho. Citando West e Anderson [1996], [Quandt et al, 2014] ressaltam que objetivos compartilhados, alto nível de participação nas interações, no intercâmbio de informações e na tomada de decisões, além de

Revista Eletrônica do Alto Vale do Itajaí - REAVI, v.08, n 13, p. 095-102, dez 2019 ISSN: 23164190, DOI 10.5965/2316419008112019095 
uma orientação para a excelência em desempenho e a existência de apoio para a inovação são fatores crucias de sucesso.

Há fatores que podem dificultar a implantação e funcionamento de um programa de ideias, como a falta de apoio da alta administração para a iniciativa, o custo de implantação do programa em relação aos resultados esperados, problemas de comunicação, a baixa participação do pessoal, e recompensas ou incentivos insuficientes à participação. Dentre esses fatores, observa-se que o perfil de gestão das empresas, no sentido de como a empresa, os gestores/os líderes agem, na geração de ideias, será preponderante [Quandt et al, 2014, p. 187].

Assim, segundo os autores apresentados, empresas que mantêm foco na aprendizagem, engajamento da liderança em prol de uma cultura inovadora, utilizam-se de ferramentas adequadas de geração e gestão da criatividade e valorizam o comportamento inovador obtêm resultados competitivos e que contribuem para o desempenho dos negócios.

\subsection{A gestão de ideias e os ambientes criativos}

Uma estratégia para aplicação de ferramentas de gestão de ideias é construir ambientes propícios para a inovação. Chibás et al [2014, p. 21] afirmam que a dificuldade para inovar será maior em departamentos mais fechados e normatizados ou naqueles em que a precisão é fundamental.

Os autores, a partir de outros estudos bibliográficos, apontam que a inovação implica romper com a forma anterior de fazer as coisas, e, como consequência, demandará novas técnicas e mudanças organizacionais, como aquelas feitas nos ambientes para que se tornem mais acolhedores, a exemplo de empresas como Google, Facebook e Walmart.com. Tais espaços passaram a ser, como afirmam [Dini et al, 2014], "copiados" por muitas empresas já que proporcionam a reunião e convívio das pessoas, o "estarem juntos" na criação de seus trabalhos (cocriação), com ambientes mais abertos e coloridos, espaços que contemplam o lúdico e privilegiam a descontração, compartilhamento e o envolvimento entre os funcionários.

\section{Metodologia}

A pesquisa realizada teve caráter exploratório e descritivo, com abordagem quantitativa. A coleta de dados foi realizada pela aplicação de um questionário aos representantes de empresas expositoras no ENIT - Feira e Encontro de Negócios, Inovação e Tecnologia, evento realizado entre os dias 18 e 20 de setembro de 2018, no munícipio de São Bento do Sul - SC. A população da pesquisa foi de 32 empresas de segmentação variada quanto ao porte e tipo de negócio, com 32 respostas válidas. Para definição de porte de estabelecimentos seguiu-se o número de empregados conforme os critérios definidos pelo [Sebrae, 2013]. Assim, considerou-se para grande porte 100 ou mais empregados para Comércio e serviços e 500 ou mais empregados para a Indústria; para médio porte 50 a 99 empregados para Comércio e serviços e de 100 a 499 empregados para Indústria; para pequeno porte de 10 a 49 empregados para Comércio e serviços e de 20 a 99 empregados para Indústria.

O objetivo da pesquisa foi identificar aspectos básicos da criatividade e gestão de ideias nas empresas, estas voltadas ao ramo da tecnologia e inovação e/ou transferência de conhecimento na região do planalto norte catarinense. Para isso, elaborou-se um formulário com 8 perguntas objetivas, mais perguntas para coleta de dados do perfil dos respondentes. A intenção foi aplicar entrevista de menos de 5 minutos, haja vista os entrevistados estarem em atendimento aos

Revista Eletrônica do Alto Vale do Itajaí - REAVI, v.08, n 13, p. 095-102, dez 2019 ISSN: 23164190, DOI 10.5965/2316419008112019095 


\section{REAVI}

visitantes da feira. Neste artigo serão apresentados resultados de 3 das 8 perguntas aplicadas. $\mathrm{O}$ trio de resultados versa sobre a presença de fatores determinantes à inovação nas empresas, a saber: a presença de estratégias de promoção e de implementação de ideias, a oferta de ambientes que propiciem a criatividade nas organizações e a compreensão da relação entre a criatividade a inovação.

\section{Resultados e Discussão}

O perfil do público entrevistado é apresentado na Figura 1. Para análise do perfil, verificouse o porte da empresa e o nível de escolaridade das pessoas que responderam ao questionário.

Figura 1 - Perfil do público entrevistado.
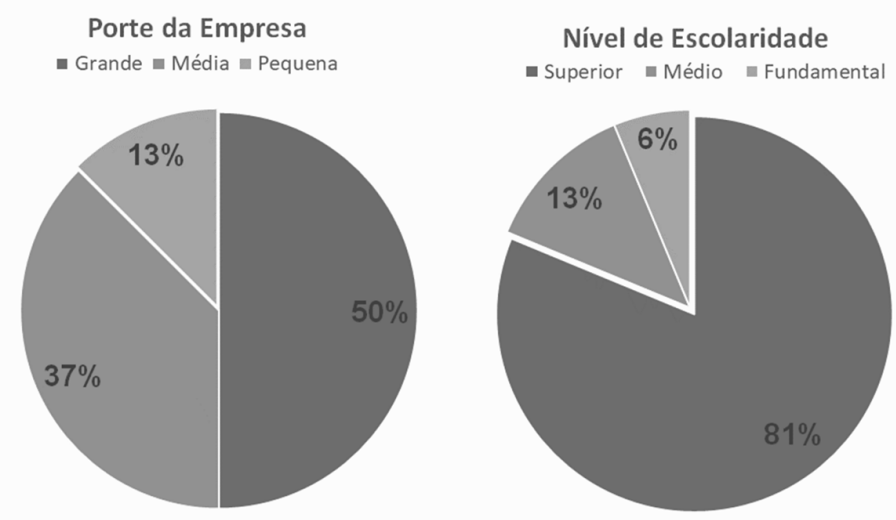

Fonte: Dados da Pesquisa.

A presença de instituições de grande porte foi mais significativa na amostra (50\%). Sua expressiva presença na amostra - e no evento - aponta a competição em produtos e serviços e a necessidade da inovação como estratégia e da tecnologia como ferramenta de mudança. Além disso, feiras deste tipo servem de observatório para grandes empresas encontrarem novos parceiros, seja em empresas nascentes e com tecnologias de ponta ou outras empresas da cadeia produtiva e uma oportunidade de interação direta com consumidores. Ou seja, eventos deste tipo propiciam um ambiente interessante para geração de ideias e inovação. Entre grandes e médias empresas, tem-se $87 \%$ da amostra, o que implica na interpretação das respostas em pensar em empresas com estratégias e sistemas de gestão internos implementados e amadurecidos, portanto com melhores condições de estruturação da gestão das ideias e da inovação, porém, por outro lado, com um desafio maior da mudança cultural entre tradicionais e inovadoras.

Chamou a atenção o nível de escolaridade superior entre os respondentes da amostra (81\%), apontando presença de capital humano qualificado e que pode apoiar as empresas na gestão de novos processos de compartilhamento de informações e na busca da inovação. Neste aspecto, destaca-se a importância de as universidades investirem em abordagens do tema inovação e criatividade em suas matrizes, melhor preparando o profissional para auxiliar as empresas no cenário atual em que criar é sinônimo de competir.

Revista Eletrônica do Alto Vale do Itajaí - REAVI, v.08, n 13, p. 095-102, dez 2019 ISSN: 23164190, DOI 10.5965/2316419008112019095 


\section{REAVI}

Figura 2 - Sua empresa utiliza alguma ferramenta para gestão de ideias?

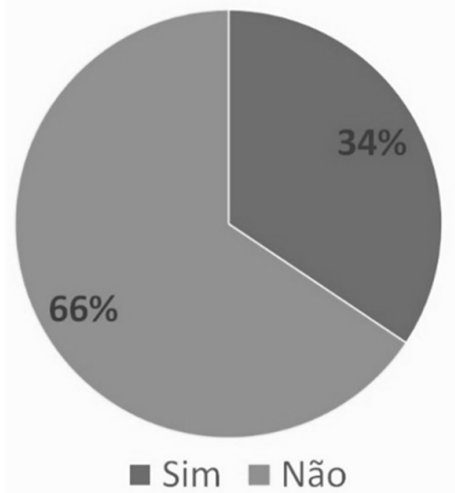

Fonte: Dados da Pesquisa.

Vê-se na Figura 2 que $66 \%$ dos respondentes deram resposta negativa sobre o uso de ferramentas para gestão de ideias, como um portal ou outros sistemas informatizados (ou não) que capturam e difundem conhecimento e experiência entre colaboradores/departamentos, ou atividades como comunidades de prática ou outras formas de gerar e gerir ideias, ou seja, dois terços da amostra não têm estas práticas incorporadas à rotina da empresa. A preocupação com inovação é discurso corrente das empresas, porém destaca-se a necessidade apontada pelos autores [Chibás et al, 2014] de que tanto a gestão da inovação quanto das ideias e da criatividade precisam andar juntas. Neste aspecto, as empresas precisam comprender mais e melhor sobre o valor do processo criativo e de sua gestão para chegar a resultados mais inovadores e, portanto, mais competitivos.

Figura 3 - Sua empresa oferece algum tipo de ambiente diferenciado, onde você possa dar uma pausa durante o período de trabalho?

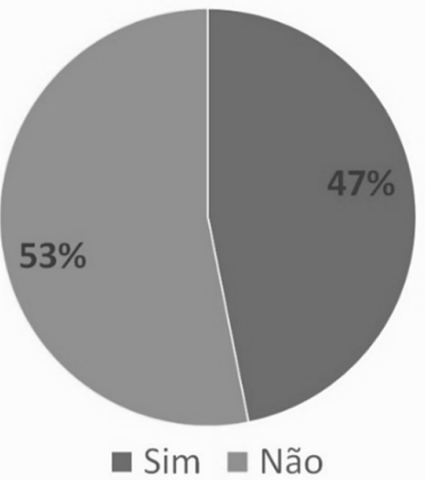

Fonte: Dados da Pesquisa

No caso da Figura 3, os resultados foram positivos à criatividade, pois mostram que praticamente metade dos respondentes (47\%) afirma possuir na empresa algum espaço diferenciado, e isto é fundamental para que a criatividade possa ser estimulada. Ambientes acolhedores e diferenciados que permitam o convívio entre as pessoas são fundamentais para que a geração de ideias e a inovação aconteçam. Por outro lado, ainda há muito a fazer junto aos $53 \%$ que disseram não ter ambientes especiais, pontos de encontro que permitam cooperação e Revista Eletrônica do Alto Vale do Itajaí - REAVI, v.08, nº 13, p. 095-102, dez 2019 ISSN: 23164190, DOI 10.5965/2316419008112019095 


\section{REAVI}

compartilhamento de experiências e conhecimento e relaxamento. Para inovar, é necessário ter empresas alinhadas às estratégias de ambientes criativos, que realmente promovam conexões, um dos pressupostos da geração de ideias.

Figura 4 - Você acredita que sua empresa pode ser mais inovadora a partir do uso das ideias dos seus funcionários?

Fonte: Dados da Pesquisa

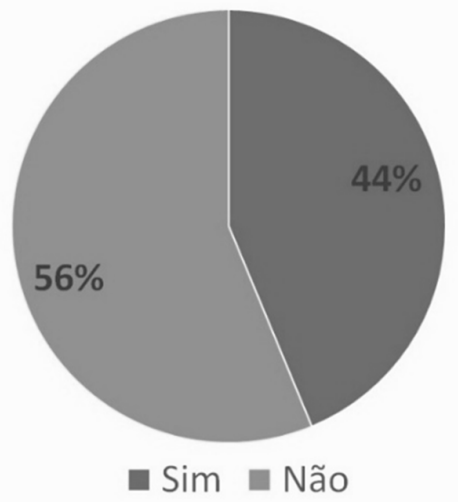

Ao focalizar na contribuição dos funcionários, os percentuais da Figura 4 não parecem indicar que o potencial criativo dos colaboradores esteja sendo bem gerido e reconhecido, já que $56 \%$ não acreditam que é por meio das ideias dos funcionários que a empresa inovará. Seria um indício de que a inovação destas empresas está desconectada dos processos criativos internos? Seria porque o foco está em resultado que venha de setores específicos e profissionais determinados e não sejam abertas possibilidades à todos? A lacuna parece estar na complexidade de lidar com mecanismos de inovação aberta e romper paradigmas tradicionais, pois a falta de ferramentas de gestão de ideias e de ambientes criativos aponta na mesma direção. Portanto, a importância da cultura organizacional voltada à aprendizagem para a inovação mostra-se como o direcionamento estratégico a ser melhor compreendido e implementado.

\section{Conclusões}

Desenvolver o potencial criativo é possível e imperativo para organizações que queiram manter-se competitivas. A criatividade é parte fundamental do processo inovativo e pode ser aprendida, gerida e mensurada.

Sabe-se que serão necessários estudos mais aprofundados e abrangentes para respostas mais consistentes sobre a cultura organizacional das empresas da região, assim como explorar melhor "comportamentos, práticas gerenciais e processos associados à gestão do conhecimento e da inovação, e seus impactos na capacidade de inovar", como alerta [Quandt, 2014, p. 176].

No entanto, os resultados permitem alertar estas empresas de que no contexto de geração de ideias pelos colaboradores, programas de geração e ferramentas de gestão de ideias como estratégia fazem-se necessários para que se possa inovar em ciclos contínuos, como se exige no cenário atual. Portanto, estratégias para criar uma cultura organizacional pró-inovação podem - e precisam - ser aprendidas, implantadas e mantidas.

Revista Eletrônica do Alto Vale do Itajaí - REAVI, v.08, n 13, p. 095-102, dez 2019 ISSN: 23164190, DOI 10.5965/2316419008112019095 


\section{REAVI}

\section{REFERÊNCIAS}

BAHIA, Sara; Ibérico-Nogueira, Sara (2005). Entre a Teoria e a Prática da Criatividade. In: G. Miranda \& S. Bahia [Orgs.]. Psicologia da educação: Temas de Desenvolvimento, Aprendizagem e Ensino. Lisboa: Relógio d'Água.

CHIBÁS, F. O. et al. (2014). Gestão da Inovação e da Criatividade Hoje: apontes e reflexões. In: HOLOS, Ano 29, Vol. 3. Disponível em:

http://www2.ifrn.edu.br/ojs/index.php/HOLOS/article/viewFile/1082/678. Acesso em: 01 de agosto de 2019.

DANIELS, Harry [Org.]. [1996]. Uma introdução a Vygotsky (2002). São Paulo: Loyola.

DINI, Patricia et al. (2014). Ambientes Criativos e o exercício da inovação. Disponível em: https://www.researchgate.net/publication/295579122. Acesso em: 01 de agosto de 2019.

LACERDA, André Pedroso de (2009). Criatividade, Pensamento e Processo Criativo. Disponível em:

http://www.pucrs.br/edipucrs/XSalaoIC/Ciencias_Sociais_Aplicadas/Desenho_Industrial/71013ANDRE_PEDROSO_DE_LACERDA.pdf. Acesso em: 01 de agosto de 2019.

NEWMAN, Fred; HOLZMAN, Lois (2002). Lev Vygotsky: cientista revolucionário. São Paulo: Loyola.

PRETTE, Zilda Aparecida Pereira Del; PRETTE, Almir Del (2010). Habilidades sociais e análise do comportamento: proximidade histórica e atualidades. In: Revista Perspectivas. vol. 01. n. 02. São Paulo.

SANTO, Rui (2015). Ferramentas para acelerar a produção de ideias. Disponível em: https://administradores.com.br/artigos/criatividade-11-ferramentas-para-acelerar-a-producao-deideias. Acesso em: 01 de agosto de 2019.

QUANDT, Carlos Olavo (2014). Programas de Gestão de Ideias e Inovação: as Práticas das Grandes Empresas na Região Sul do Brasil. In: Revista de Administração e Inovação. São Paulo, v. 11, n.3, p. 176-199, jul./set.

VIGOTSKI, Lev Semenovich (2007). A formação social da mente. São Paulo: Martins Fontes [1978].

(2001). A construção do pensamento e da linguagem. Trad. Paulo Bezerra. São Paulo: Martins Fontes [1934].

WESCHLER, Solange M. (1998). Avaliação multidimensional da criatividade: uma realidade necessária. In: Psicologia Escolar Educacional. vol.2 no.2 Campinas.

Revista Eletrônica do Alto Vale do Itajaí - REAVI, v.08, n 13, p. 095-102, dez 2019 ISSN: 23164190, DOI 10.5965/2316419008112019095 